\title{
Esophageal variceal ligation
}

JOHN S GOFF, MD

\begin{abstract}
Endoscopic sclerotherapy is an effective method for treating and eradicating acutely bleeding varices in repeated sessions; however, it is not ideal because of numerous serious complications. Endoscopic variceal ligation, developed to circumvent some of the side effects of sclerotherapy, controls actively bleeding varices in about $90 \%$ of cases. Of 146 patients treated with endoscopic variceal ligation, variceal eradication was achieved in $80 \%$ of surviving patients in a mean of 5.5 treatment sessions. Recurrent bleeding developed in $39 \%$. Complications were very rare. It is concluded that endoscopic variceal ligation is at least as effective as sclerotherapy but associated with fewer complications. Can J Gastroenterol 1990;4(9):639-642
\end{abstract}

Key Words: Bleeding, Ligation, Sclerotherapy, Varices

\section{La ligature des varices oesophagiennes}

RESUME: La sclérothérapie endoscopique permet de traiter efficacement les varices hémorragiques aiguës et les élimine après des séances répétées; ce n'est toutefois pas la méthode idéale parce qu'elle s'accompagne de complications graves et nombreuses. La ligature endoscopique des varices a été mise au point pour contourner les effets indésirables de la sclérothérapie. Dans près de $90 \%$ des cas, la ligature endoscopique des varices peut contrôler efficacement les varices qui saignent activement. Parmi nos 146 patients traités initialement par ligature endoscopique des varices, l'éradication des varices a abouti chez $80 \%$ des survivants, en une moyenne de 5,5 séances. Une récidive hémorragique est survenue dans $39 \%$ des cas. Les complications de la ligature endoscopique des varices étaient très rares. L'auteur conclut que la ligature endoscopique des varices est pour le moins aussi efficace que la sclérothérapie mais qu'elle implique un nombre moindre de complications.

University of Colorado Medical Center, Denver Veterans Administration Hospital, Denver, Colorado, USA

Correspondence and reprints: Dr JS Goff, 4200 E 9 th Avenue, B 158, Denver, CO 80262 , USA. Telephone (303) 270-7131
E NDOSCOPIC TREATMENT OF BLEEDing esophageal varices was first successfully performed in 1936 (1), but did not become popular because of the development of the portacaval shunt operation. Only in the late 1970s did convincing studies appear regarding the efficacy of endoscopic sclerotherapy (24). With the increased use of safer and easier to use flexible endoscopes, endoscopic sclerotherapy has been used and studied widely. Other endoscopic methods have since been introduced, including laser coagulation, polymer injections and mechanical ligation. Endoscopic sclerotherapy is an effective means for controlling acute variceal hemorrhage and preventing recurrent hemorrhage if repeated until varices are obliterated (5). The major disadvantage of sclerotherapy is the $20 \%$ or greater side effect rate (6). The side effects include pain, dysphagia, fever, pleural effusions, esophageal strictures, esophageal ulcers, mediastinitis, bleeding and esophageal perforation. The deep ulcers created by the sclerosant in many patients are the primary reason that an alternative therapy has been sought. 


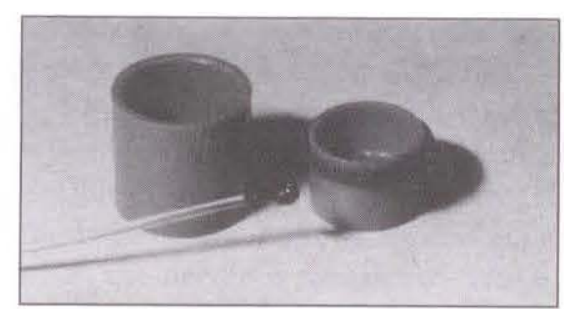

Figure 1) Endoscopic ligating device. The larger cylinder is attached to the tip of the endoscope. The tripwire is passed down the biopsy channel of the endoscope and hooked inside the smaller cylinder. The small cylinder is preloaded with the black O-ring, and once attached to the tripwire, is seated within the large cylinder on the tip of the endoscope

At the University of Colorado, a device has been developed that is attached to the end of an endoscope and can be used to place small elastic $\mathrm{O}$. rings around esophageal varices in a manner similar to hemorrhoidal ligation $(7-10)$. The device consists of two plastic cylinders, a tripwire, and the $\mathrm{O}$ ring (Figure 1). The larger of the two cylinders is attached to the end of the endoscope, while the O-ring is stretched over the smaller cylinder. The tripwire is passed through the biopsy channel of the endoscope and attached to the smaller of the cylinders. The smaller cylinder is then seated in the larger cylinder at the end of the endoscope. With this arrangement, pulling the tripwire slides the smaller cylinder further into the larger one and strips off the O-ring.

Endoscopic variceal ligation is done on patients currently bleeding or who have recently bled from esophageal varices. The endoscope is passed through the patient's mouth in the standard fashion. An overtube is placed on the shaft of the endoscope so that the endoscope can be used as a guide for passing the overtube (Figure 2). The author has been using a custom-made overtube $25 \mathrm{~cm}$ long with a built-in mouth piece at one end. The overtube allows repeated passage of the endoscope without excessive trauma to the pharyngeal area. Once the endoscope is passed and the overtube in place, a thorough endoscopic examination is performed. The endoscope is then removed, the endoscopic variceal ligation device placed on the tip of the

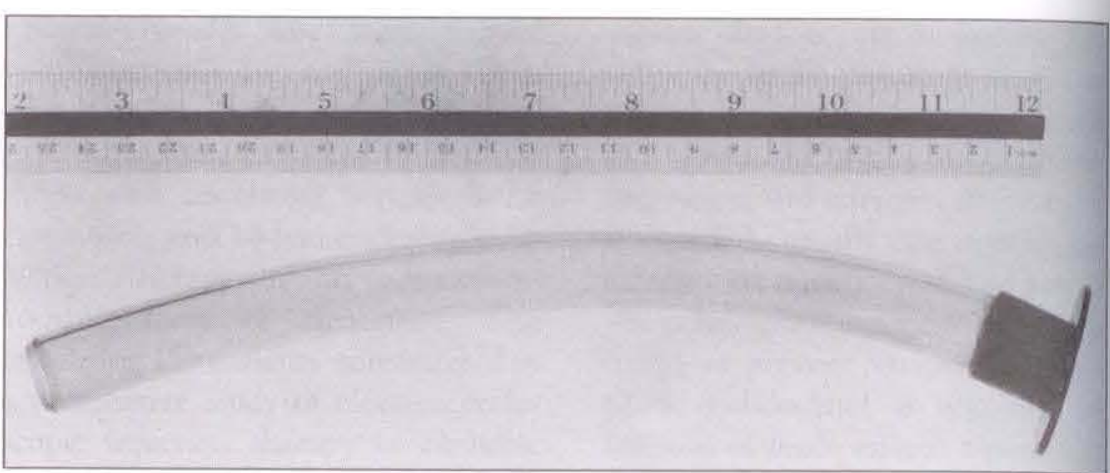

Figure 2) Overtube for use with the ligation device. The tube is semiflexible with a beveled distal itp and a rigid mouth piece built in to the proximal end
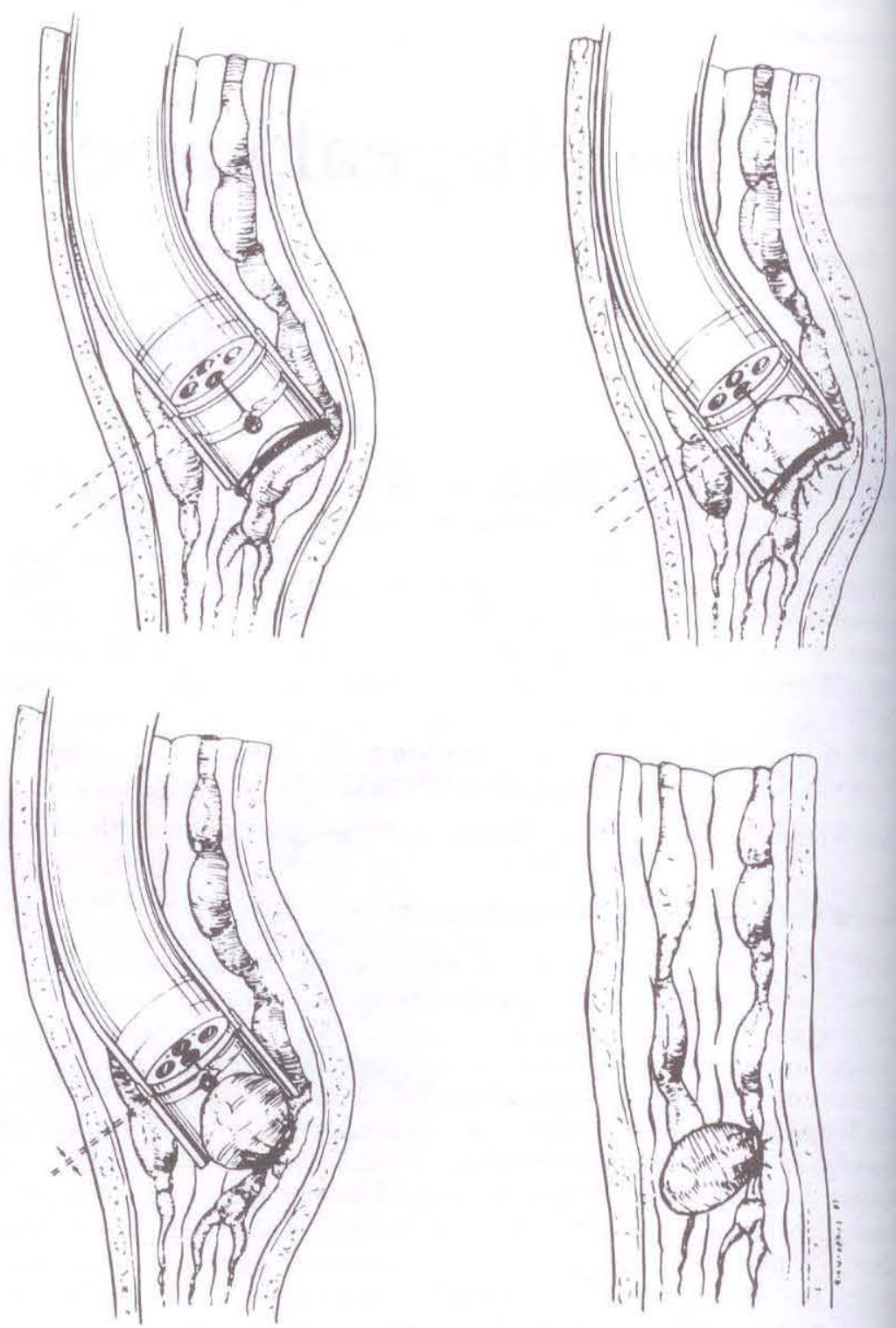

Figure 3) Endoscopic ligation technique. Upper left The ligating device is approximated to the varix in the wall of the esophagus. Suction is applied and tissue containing the varix is aspirated into the deadspace within the ligating device (Upper right). Lower left The situation immediately after the endoscopist pulls on the guidewire and releases the O-ring around the aspirated tissue. Lower right The final product 




Figure 4) Endoscopic view of a ligated varix. The dark ball in the centre is the ligated varix. The base where the band is located is to the right

endoscope, and the whole thing repassed through the overtube into the distal esophagus. The endoscope tip is positioned over a variceal column in the distal esophagus at or just below the $Z$-line. Suction is applied to draw the esophageal mucosa and varix up into the deadspace created by the two cylinders at the tip of the endoscope. When the tissue is fully inside the cylinders, the tripwire is pulled and the O-ring slipped around the tissue bolus. The endoscope is removed, reloaded with a fresh $\mathrm{O}$-ring, and repassed into the esophagus (Figure 3).

The procedure is repeated as many times as needed until all varices are ligated at least once (Figure 4). The number of $\mathrm{O}$-rings placed will vary from one to 12 . The whole process is repeated after one week and every two weeks after that until all varices are visibly gone. The patients are followed with repeat endoscopies every three to six months to ensure no varices recur.

The first 146 patients treated with endoscopic variceal ligation had a mean age of 52 years; 96 of them were men. Ninety-three had Laennec's cirrhosis. Using the modified Child-Pugh system, patients were equally divided between three classes $(A, B, C)$. One hundred and thirty-two of the patients had ceased bleeding prior to the first session, while the other 33 were still actively bleeding. Of the patients not actively bleeding, $5 \%$ did not survive the initial hospitalization, while $43 \%$ of the active bleeders did not survive. Overall, the fatality rate for the entire duration of the study (mean follow-up 15 months) was $27 \%$. Of those who survived their initial hospitalization, $57 \%$ experienced 72 episodes of recurrent hemorrhage before their varices were eradicated. In general, it took an average of five sessions and $18 \mathrm{O}$-rings to eradicate a patient's varices. All of these figures are comparable to those seen in patients treated with repeated sclerotherapy sessions, except the complication rate. Only three patients developed nonbleeding complications: a meat impaction without significant stricture, and two strictures that required a solitary dilation (Table 1).

Active variceal hemorrhage was controlled in $90 \%$ of patients. Two of the uncontrollable patients had undergone sclerotherapy at other hospitals before endoscopic variceal ligation and had resultant large esophageal ulcerations. Endoscopic variceal ligation also produces esophageal ulcerations, but these are superficial and have resulted in a low incidence of bleeding $(11 \%)$ despite the presence of major coagulation problems in many of the patients.

Recurrent esophageal varices developed in approximately one-third of patients who had long term followup. These were easily re-eradicated with one or two further sessions which is comparable to the experience reported for sclerotherapy.

In the actively bleeding patient, there may be two advantages to endoscopic variceal ligation over sclero- therapy besides those described above. The placement of the $\mathrm{O}$-ring need only be near a variceal column to be effective, while sclerotherapy should be done intravariceally, if at all possible, to avoid complications from the sclerosant necrosing the esophageal wall. Intravariceal injections can be very difficult in the presence of large amounts of blood in the esophageal lumen. Use of the overtube may prevent aspiration during a procedure on an actively bleeding patient because it directs the gastric and esophageal contents out of the patient's mouth and thus protects the airway. Endoscopic variceal ligation may offer an advantage over sclerotherapy because it is simple to perform, has fewer complications, and may be equally effective. Whether it is truly as effective or more effective than sclerotherapy is yet to be proven, but a retrospective comparison at the author's hospital strongly suggested this conclusion (11). The author is currently testing this hypothesis with a multicentre, randomized trial comparing the two techniques.

The question remaining is whether or not a more efficient endoscopic method for eradicating esophageal varices can be developed so that there will be a shorter time between initiation of therapy and variceal eradication. This would be desirable, since most rebleeding occurs during the interval before total variceal eradication is achieved. Preliminary work at the author's hospital has suggested that a combination of endoscopic variceal

\section{TABLE 1}

Esophageal variceal ligation (EVL) results at 36 months

\begin{tabular}{|c|c|c|c|}
\hline & & Alcoholic cirrhosis & Nonalcoholic cirrhosis \\
\hline \multicolumn{2}{|c|}{ Number of patients } & 93 & 53 \\
\hline \multicolumn{2}{|c|}{ Mean age (years) } & 52 & 53 \\
\hline \multicolumn{2}{|c|}{ Female/male } & $21 / 72$ & $29 / 24$ \\
\hline Childs-Pugh & $\begin{array}{l}A \\
B \\
C\end{array}$ & $\begin{array}{l}29 \\
34 \\
30\end{array}$ & $\begin{array}{r}25 \\
19 \\
9\end{array}$ \\
\hline \multicolumn{2}{|c|}{ Mean follow-up (months) } & 15.6 & 15.2 \\
\hline \multicolumn{2}{|c|}{$\begin{array}{l}\text { Active bleeding (\%) } \\
\text { Percentage controlled }\end{array}$} & $\begin{array}{l}20(21) \\
90 \%\end{array}$ & $\begin{array}{l}13(24) \\
100 \%\end{array}$ \\
\hline \multicolumn{2}{|c|}{ Variceal eradication } & $80 \%$ & $78 \%$ \\
\hline \multicolumn{2}{|c|}{ Mean number of EVL sessions } & 5.6 & 5.4 \\
\hline \multicolumn{2}{|c|}{ Recurrent bleeding (\%) } & $47(50)$ & $10(30)$ \\
\hline \multicolumn{2}{|c|}{ Overall survival } & $74 \%$ & $72 \%$ \\
\hline
\end{tabular}


ligation and sclerotherapy is able to eradicate gastric and esophageal varices more quickly than either method alone.

\section{REFERENCES}

1. Crafoord C, Frenckner P. New surgical treatment of varicose veins of the esophagus. Acta Otolaryngol 1939;27:422-9.

2. Wodak E. Akute gastrointestinale blutung: Resultate der endoskopischen sklerosierung von osophagusvarizen. Schweiz Med Wochenschr 1979;109:591-6.

3. Paquet KJ, Oberhammer E. Sclerotherapy of bleeding oesophageal varices by means of endoscopy. Endoscopy 1978;10:7-12.
4. Terblanche J, Northover JM, Bornman P, et al. A prospective evaluation of injection sclerotherapy in the treatment of acute bleeding from esophageal varices. Surgery 1979;85:239-45.

5. Infante-Rivand C, Esnaola S, Villeneuve JP. Role of endoscopic sclerotherapy in the long-term management of variceal bleeding: A metaanalysis. Gastroenterology 1989;96:1087-92

6. Schuman BM, Beckman JW, Tedesco FJ, Griffin JW, Assad R. Complications of endoscopic injection sclerotherapy: $A$ review. Am J Gastroenterol 1987;82:823-9.

7. Stiegmann GV, Sun JH, Hammond W Results of experimental endoscopic esophageal varix ligation. Am Surg 1988;54:113-8.
8. Stiegmann GV, Goff JS. Endoscopic esophageal varix ligation (EVL) Preliminary clinical experience. Gastrointest Endosc 1988;34:105-8.

9. Stiegmann GV, Goff JS, Sun JH, Wilborn S. Endoscopic elastic band ligation for active variceal hemorrhage. Am Surg 1989;55:124-8.

10. Goff JS, Reveille RM, Stiegmann GV Endoscopic sclerotherapy versus endoscopic variceal ligation: Symptoms, complications, and motility. Am J Gastroenterol 1988;83:1240-4.

11. Goff JS, Stiegmann GV. Esophageal variceal hemorrhage medical therapy (C) vs sclerotherapy (ES) vs endoscopic variceal ligation (endoscopic variceal ligation): A retrospective study. Am J Gastroenterol 1988;83:1063. 


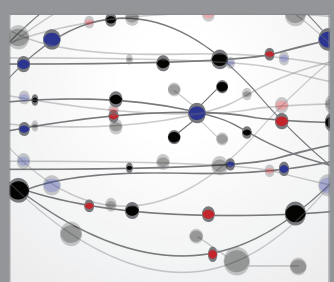

The Scientific World Journal
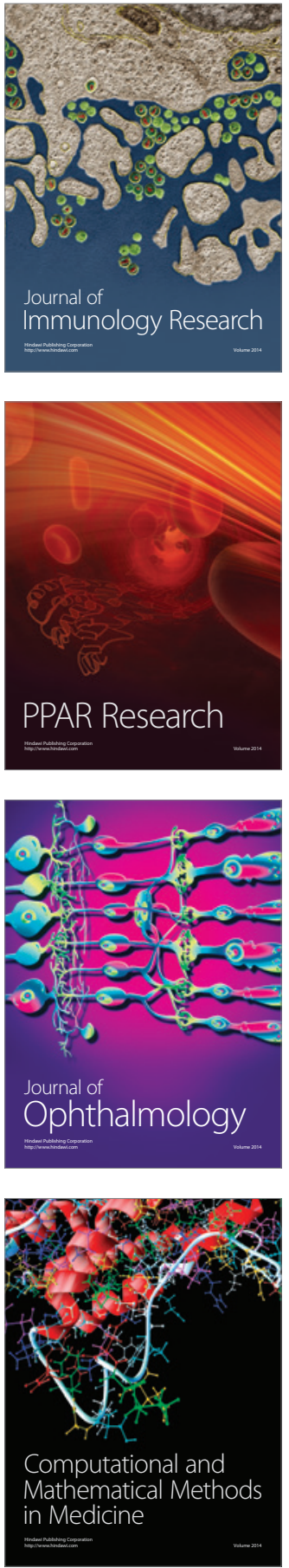



Gastroenterology Research and Practice

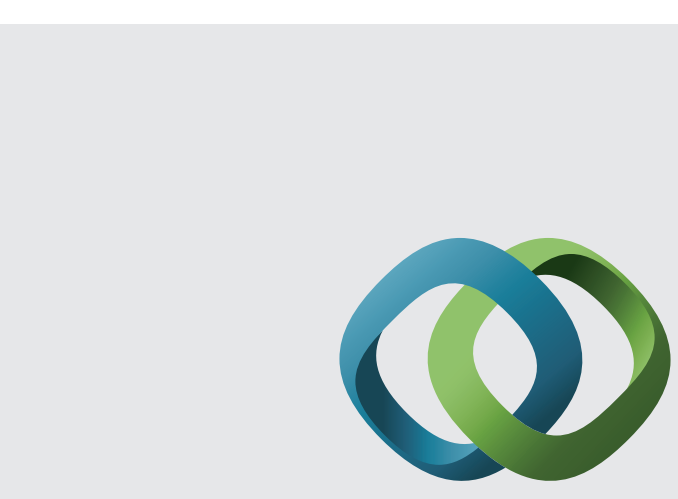

\section{Hindawi}

Submit your manuscripts at

http://www.hindawi.com
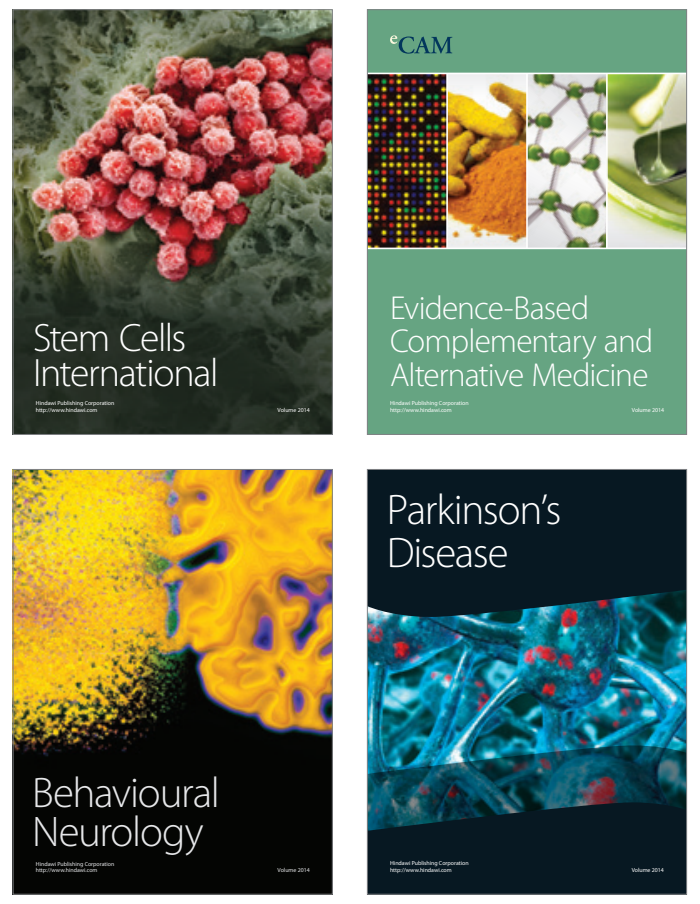
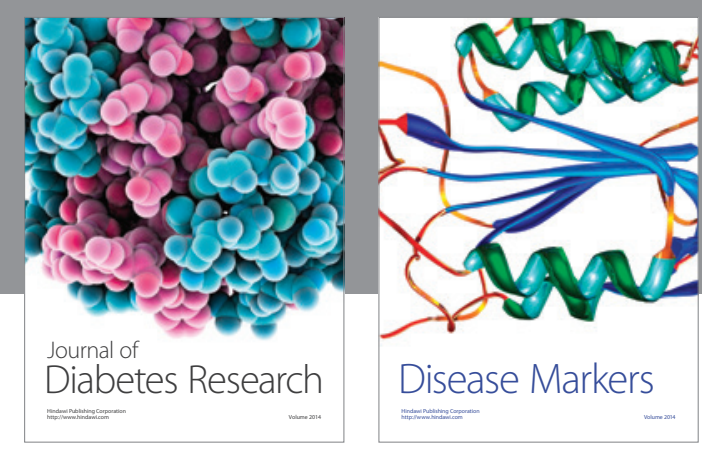

Disease Markers
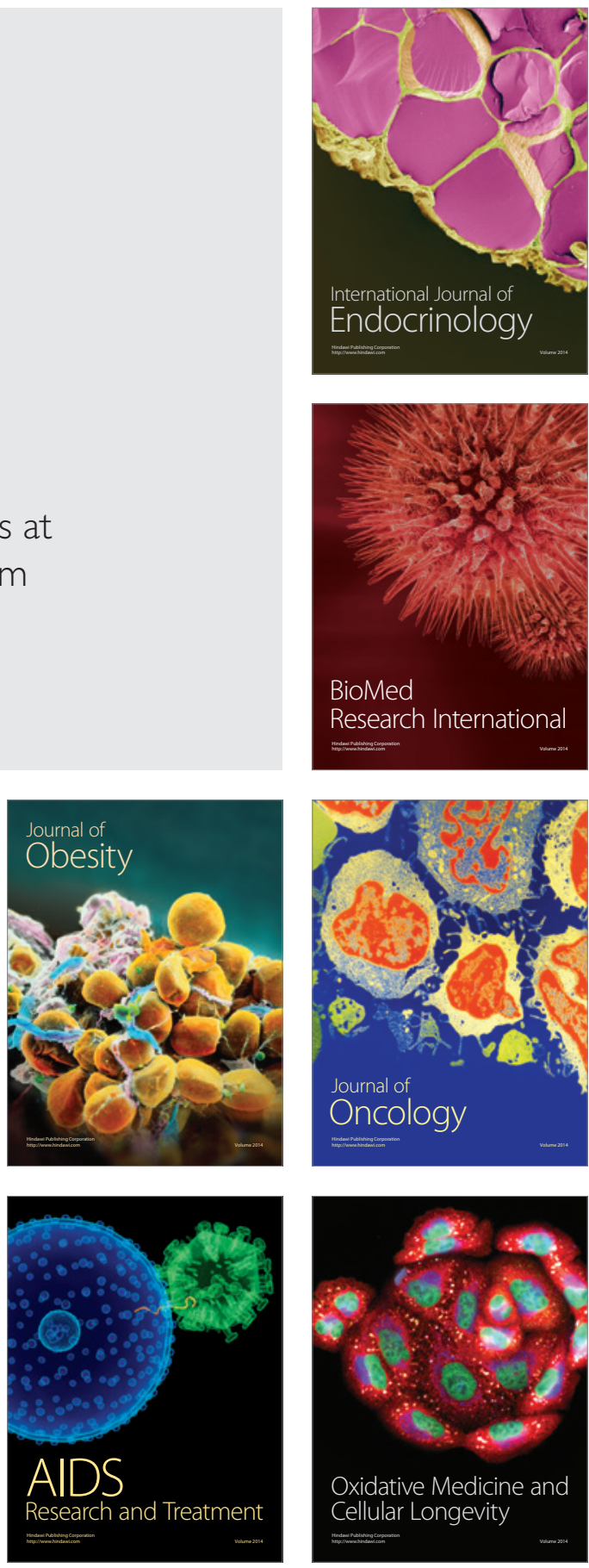